\title{
ON IMPROVED INDIA-RUBBER SPRINGS FOR RAILWAY ENGINES, CARRIAGES, \&c.
}

In order to explain the difficulties which have been contended with and surmounted by the use of these springs, the condition of the roads upon which they have produced such satisfactory results has to be noticed, and the causes which first led to the introduction of Indiarubber as a substitute for steel, in bearing springs, buffers, and draw springs. 
The Western Valleys Lines of the Monmouthshire Railway and Canal Company, (upon which the writer is Locomotive Superintendent,) consist of twenty-five miles of tramway, exclusive of branches, and worked by heavy coupled engines of the most improved construction. The tramplate is laid by means of chairs upon transverse sleepers, about 3 feet apart, and an intermediate sleeper at the joints. This plate, although heavy, (about $73 \mathrm{lbs}$. per yard) is of very weak section, as shown by the accompanying drawing, Fig, 4, Plate 9 , and there is consequently considerable deflection in it, a tendency to rise at the joints, and for the sleepers to work loose; the effect of this is, to cause a much greater expenditure of power necessary to overcome a series of rising and falling gradients, than would be the case upon an edge rail, and an undulatory motion of the engine is caused, which is extremely destructive to the steel springs hitherto in use on this line. The curves are also unusually sharp, (some being under five chains radius, and the majority under twenty chuins,) which is productive of a prejudicial effect on the wheels, buffers, and other parts of the engines, carriages, and waggons. The gradients are very heavy, (some being 1 in 54,) producing a much greater strain on the draw-bars and couplings than is to be met with upon ordinary railways.

Upon such a road, the inconveniences attending the use of steel springs were both numerous and formidable. In addition to the continual repairs which were required by the springs themselves, the injury done to the permanent way, arising from the unequal action of the springs, and the violent concussions they were subject to, when they were totally disabled (as was frequently the case), was large in amount and of continual occurrence, and of a character that involved considerable expense in repairs. Some idea of the damage thus occasioned may be formed from the fact of the wheel tyres requiring to be replaced at least every eight months, having become worn by that time into a series of flats, more nearly resembling an irregular polygon in outline than the circumference of a circle.

Fig. 4 shows a section of the engine tyres used on the tramways: they are steeled on the wearing surface. With regard to the springs themselves, it may be proper to mention here that the item of expenditure for steel springs (including wages for repairing them) was $£ 2519 \mathrm{~s} .9 \mathrm{~d}$. in six months, for fifteen engines only. 
Such then were the circumstances when it was deemed necessary to test the application of India-rubber to the various purposes before mentioned, and the results have been attended with such marked success, as to exceed the most sanguine anticipations entertained.

The India-rubber Springs described in this paper are constructed on Mr. Coleman's plan. Fig. 1, Plate 9, represents the first form of application, for engine-bearing springs. It consists of a cylinder of prepared India-rubber A, 9 inches long and 9 inches in diameter, with a hole through it of 13 inch for the spring pin; it is supported by a wroughtiron plate $1 \frac{1}{8}$ inch thick, which rests on a shoulder on the spring-pin, and is covered by a wrought.iron plate and crossbar, through which pass the spring links attached to the outside framing at the bottom, and secured by set and jam nuts at the upper end. The Indiarubber is prevented from undue lateral expansion by two $\frac{3}{4}$-inch round iron hoops, and from internal compression and friction on the spring pin, by a helical coil of strong wire; instead of this wire, wroughtiron ferrules are now used. To obviate an insonvenience which has been occasionally complained of, in passing over unusually rough portions of the road, viz., the jumping motion of the engines, from the great elasticity of the springs-it was found necessary to insert between the bottom plate and the top of the framing another smaller cylinder of Iudia-rubber B, for the purpose of absorbing the recoil of the spring, and to prevent any motion being recommunicated from the spring to the framing. This had the desired effect, and the engine was found afterwards to run uniformly steady, at all varieties of speed, and how. ever great the inequalities of the road.

Upon engines with inside framing, or where sufficient space for the springs could not be obtained, two cylinders or sometimes three were used, AAA, as in Fig. 2, which represents the springs in use on the engines Nos. 2, 3, 4, and 5 .

In the application of the same deseription of spring to a tender, the India-rubber is $6 \frac{1}{2}$ inches diameter, 7 inches long, with a $1 \frac{3}{4}$ inch hole, and bears against a cast-iron bracket bolted to the framework of the tender, the bottom plate being supported by a set nut on the spring pin, which passes loosely through a hole in the underside of the bracket, and rests on a wrought-iron plate, $\frac{5}{8}$ inch thick, made to fit in the top of the axle-box. 
Fig. 3 shows a similar arrangement applied to waggons. In the passenger carriages, two of these springs are used in pairs, in order to obtain a greater amount of elasticity, without increasing the distance between the centre of the axle and the sole bar, and a modified form of axle-box is introduced, to meet the requirements of the double cylinder of India-rubber. No horn plates are used in this case, their place being supplied by two guide rods, which pass through the axle-box and Indiarubber cylinders, being firmly bolted to the sole bar by jaws on the upper ends, and kept in their places by diagonal stays at the lower ends. The axle-box is cast with a projecting hollow wing on each side, which is enlarged on the top, to afford a bearing for the bottom of the India-rubber cylinder. and leaving a capacious grease-box between them. The upper ends of the India-rubber'cylinders are received into a castiron plate, fixed to the sole bar, and the arrangement of internal coil, or ferrules, and external hoops, is the same as previously described, with this exception, that one binding hoop only is used on each cylinder instead of two, in the case of waggons, rather greater elasticity being required for carriages. Some new passenger carri ${ }^{\mathrm{i}}$ ages with this description of spring are now in use on the Monmoutbshire Railway.

Fig. 7, Plate 10, shows the present improved form of Engine-Bearing Springs, termed the Hydro-Pneumatic Spring. The object of this form is to obtain the same amount of elasticity with a less quantity of Indiarubber, and is accomplished by thinning the cylinder of India-rubber AA internally, and in the increased space thus obtained placing a quantity of fluid B-water is used for this purpose-which, acting by hydrostatic pressure, distributes the pressure equally over every part of the internal surface, thus obtaining a much larger bearing surface than if the pressure were confined to the ends, and in fact producing precisely the same effect as a solid homogeneous cylinder of India-rubber. The fluid does not entirely fll the cavity in the India-rubber, at least not when first put in, but is adjusted to do so only on the spring receiving the maximum of impact; the air at the same time, which had before occupied the space left vacant by the fluid, retires into a chamber $C$ for that purpose in the upper part of the casting, and being then in a state of considerable condensation, exerts a powerful elastic force, assisting the spring to regain its equilibrium The air and fluid are prevented from escaping under the ends of the India-rubber cylinder by that part 
of the casting which receives them being cast with a groove, so that on the application of pressure, the India-rubber forces itself into the minutest crevice, and a perfectly tight joint is obtained without the necessity of interposing any other substance.

A spring on this principle is applied to waggons in the same manner as the spring in Fig. 3, of very simple construction, and one that requires no alteration of horn plates or axle-boxes, but which, with a very little labour, may be applied to any existing waggon adapted for steel springs.

Fig. 8 shows the same spring, as applied to some new engines, now being made for this railway. In this case the spring is entirely beneath the footplate, in a hollow part of the framing, immediately above the axle guides, by which great compactness is obtained with increased strength of the frame. The internal arrangement is the same as shown in Fig. 7, but the spring piston DD is here cast in one piece with the axle-box, thus avoiding the necessity of using a spring pin, and at the same time dispensing entirely with suspending links, nuts, and bolts, thereby still further reducing the total weight of the spring, which in this case is brought to a minimum.

Fig. 6, Plate 9, represents the Pneumatic Buffer, in which the elasticity of a cylinder of India-rubber AA is combined with that of a column of enclosed air B. No fluid is used in this case, the position of the buffer and its mode of action not being favourable to its use; neither is it required, as buffers should be sensitive, more so than would be the case were fluid used. The transverse pins $C C$, riveted to the external or wrought-iron cylinder, serve to confine the fixed and moving part of the buffer, and pass through slots in the plunger to allow them sufficient play. In a cheaper form of this buffer, the external wrought-iron case $D$ is replaced by a cast-iron one, for use where not liable to severe cross strains, Fig. 6 being only for extra strong buffers.

Fig. 5 shows a Draw Spring for the buffer plank of an engine, and Fig. 9, Plate 10, is a cheaper form (though equally efficient) for common waggons; and these are alike in principle, and only differ in their form and getting up.

The advantages resulting from the use of these springs may be thus enumerated :- lst, Reduction of Dead Weight. This item is more 
extensive than appears at first sight, since the reduction of weight is not confined to the springs themselves, but extends, in a greater or less degree, to a variety of other parts of the engine, carriage, or waggon, on account of the smoothness of their action. This is particularly advantageous in the case of cast-iron, whose liability to fracture consists, not so much in the weight it has to carry, as its inability to resist strains, jerks, and concussions; these are, however, nearly altogether deadened by the use of these springs, so that a motion uniformly smooth and steady takes the place of one that is very injurious to railway plant, especially to engines; and as the working portions of an engine are made extra strong, with a view to resist the concussions they are subject to with steel springs, it follows that when these are no longer allowed to operate, they may be made lighter without in the least impairing their efficiency. The reduction in the springs themselves is, however, considerable; and the weight thus gained is valuable, particularly in the case of waggons, where it becomes arailable for tonnage. The amount of this reduction of weight varies, as shown by the following table, but may be taken on an average at from $3 \frac{1}{2}$ to $5 \mathrm{cwt}$. per engine, and the same for waggons.

Comparative Weight of India-mubber and Steel Springs.

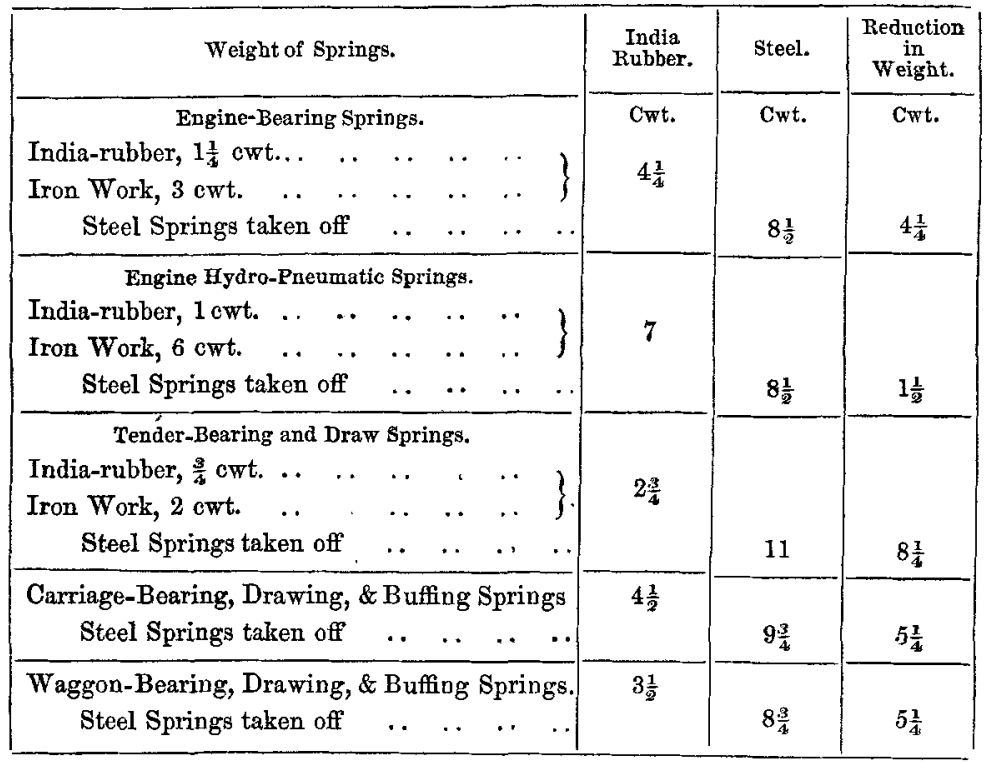


2ndly, Steadiness of Motion. This has been referred to before, and it may be added that the great steadiness of the engines with the India-rubber Springs is the surprise of every one who has witnessed their performance upon the imperfect road on which they are worked.

3rdly, Durability. Although sufficient time may not have elapsed to test the absolute durability of these springs, yet during the time they have been in use, in consequence of the heaviness of the work, if deterioration had commenced ever so slightly, it would have been observable; but in a large number of the India-rubber Cylinders that were examined, after being at work for various periods, varying from four to six months, in both engines, carriages, and waggons, in no instance was the slightest alteration visible from the day in which they were first used, nor the slightest permanent contraction in length or expansion in diameter perceptible: it may, therefore, be inferred that their durability far exceeds anything hitherto applied to the same purpose, and is fully equal to any reasonable expectation or requirement. The specimens before the meeting have been in use for the last five and six months, and corroborate this statement. The weight on each pair of the engine springs is from $4 \frac{1}{2}$ to $9 \frac{1}{4}$ tons.

4thly, Saving in Repairs. The simple construction of these springs renders it almost impossible for any injury to happen to them, consequently little or no repairs are needed. As stated before, the cost of repairing the steel springs of fifteen engines for six months was $£ 2519 \mathrm{~s} .9 \mathrm{~d}$. The cost of repairing the India-rubber Springs of fourteen engines during the last six months was only $£ 118 \mathrm{~s}$. The saving, in the cost of repairs is not confined to the springs alone, but the engine itself, the carriages and waggons to which they are applied, and even the permanent way, share the advantage. It is found that fewer chairs are broken, fewer rails (plates rather) are bent, less grease and oil is used for the bearings, and the cost of maintaining the waggons is reduced when India-rubber is used.' It is inferred with a considerable degree of probability, that from the absence of any jerk upon the axles, the tendency of the iron to become crystallized or altered in its nature and suddenly fracturing, so often complained of, and which has produced so many serious accidents upon railways, will by the use of these springs be nearly overcome, and the axles remain perfect for a much longer period, more especially as under the India. rubber Springs they show no tendency to heat. 
5 thly, Cost. The question of first cost does not properly belong to this paper, but it will be sufficient to state that a well-constructed India-rubber spring ought not, in any case, to exceed the cost of a steel spring of equal strength; but on the hydro-pneumatic principle it will be found to be considerably cheaper, especially for engines, amounting on an average to twenty per cent. saving on the old plan.

The foregoing remarks have been made chiefly with reference to Bearing Springs, but they apply equally to both Buffer and Draw Springs; and in proportion to the extent in which India-rubber is used in place of steel, does the improvement in the rolling stock become apparent, and the benefits resulting from its use more strongly developed. The Pneumatic Buffers, it is considered, have been subjected to a peculiarly severe test, few lines of railway in the kingdom possessing such disadvantageous circumstances. Almost every other description of buffer had been tried previously with the same want of success, until, from repeated failures, the attempt to obtain a permanent buffer was almost abandoned in despair, and solid blocks of wood were substituted for them in many instances. With these buffers, however, no fuilure has taken place, nor in any instance has their elasticity diminished in the slightest degree. In the accompanying table, the deflection of this description of buffer and the several kinds of springs, under different weights, is shown.

\section{Table of Deflection of Springs.}

\begin{tabular}{|c|c|c|c|c|c|c|}
\hline \multirow{2}{*}{ Load. } & $\begin{array}{l}\text { Fngine } \\
\text { Single } \\
\text { Spring. }\end{array}$ & $\begin{array}{l}\text { Engine } \\
\text { T'riple } \\
\text { Spring. }\end{array}$ & $\begin{array}{c}\text { Engine } \\
\text { Hydro- } \\
\text { Pneumatic. }\end{array}$ & $\begin{array}{l}\text { Wargon } \\
\text { spring. }\end{array}$ & $\begin{array}{l}\text { Buffer } \\
\text { Spring. }\end{array}$ & $\begin{array}{l}\text { Draw } \\
\text { Spring. }\end{array}$ \\
\hline & Fign. 1 , & Fig. 2. & Fig. 7. & Fig. 3. & Fig. 6. & Fig. 9 , \\
\hline & Ins. & Ins. & Ins. & Ins. & Ins. & Ins. \\
\hline$\frac{1}{2}$ ton. & $\frac{5}{6}$ & $\frac{1}{4}$ & $\frac{5}{8}$ & $\frac{7}{8}$ & $\frac{3}{16}$ & 1 \\
\hline 1st ton. & $\frac{1}{2}$ & $\frac{1}{9}$ & $\frac{7}{8}$ & $1 \frac{1}{4}$ & $\frac{3}{4}$ & $1 \frac{1}{2}$ \\
\hline $2 \mathrm{nd}$, & $\frac{3}{8}$ & $\frac{1}{2}$ & $\frac{1}{4}$ & $\frac{5}{8}$ & $\frac{3}{8}$ & 1 \\
\hline 3rd " & $\frac{9}{8}$ & $\frac{3}{4}$ & $\frac{1}{8}$ & $\frac{1}{2}$ & $\frac{3}{16}$ & $\frac{5}{8}$ \\
\hline 4th " & $\frac{3}{8}$ & $\frac{1}{4}$ & $\frac{1}{16}$ & - & $\frac{1}{8}$ & - \\
\hline 5 th & $\frac{3}{8}$ & $\frac{1}{4}$ & $\frac{1}{x^{\prime}}$ & - & $\frac{3}{16}$ & - \\
\hline 6th , & $\frac{3}{8}$ & - & - & - & $\frac{8}{10}$ & - \\
\hline
\end{tabular}

Before the application of India-rubber draw springs to the engines and tenders, the couplings were frequently brealing, and also the frame 
ends; but since their adoption nothing of the kind takes place. Such are the advantages of these springs that their adoption promises to become general, and it, will be shortly, without doubt, as rare to meet with a waggon unprovided with a draw spring, as it was formerly to meet with one.

In working 15,000 miles, the cost of repairs is found to be reduced in the engines using India-rubber springs, in corresponding engines of the two classes, from $5 \frac{3}{4} d$. to $3 \frac{3}{4} d$. per mile, and from $7 d$. to $3 \frac{1}{4} d$. per mile.

It has been the writer's object in this paper to state rather what has been done than to speculate on what will be; but it is notorious that the ordinary steel springs are deficient in point of general efficiency, whether as regards elasticity, durability, or cheapness. It may be that competition may cause their manufacture to be less strictly attended to than formerly; or it may be, and most likely is, that the requirements of the present day have outstripped their ability to perform. However, be that as it may, it is well known that a substitute which shall combine the above requisites has been long desired ; and the writer's hope, therefore, that this desideratum will now be supplied by the springs which have been described must be his apology for bringing the subject before the Institution.

Mr. Craig exhibited a set of the different descriptions of Indiarubber Springs described in the Paper, and also specimens of the India-rubber Cylinders, taken out of various springs which had been at work on the Monmouthshire Railway, to show the effects of wear upon them. One cylinder had worked 8,850 miles in the bearing spring of an engine; another 14,060 miles in a carriage bearing spring; and an engine buffer spring that had been six months in constant use; all of them appearing uninjured by the work, not having suffered any permanent compression.

Mr. H. Wright observed that he had seen these India-rubber Springs at work on the Monmouthshire Railway, and they certainly worked very satisfactorily; and were much better adapted to that situation than steel springs. The case of that railway was 
very peculiar; it was perhaps the worst in the kingdom for destructive action on the springs, from the great inequality and roughness of the road, which was not upon the edge-rail, but the old tramway system, and with very sharp curves; it was, indeed, impossible for steel to stand in the engine springs, and the steel springs were disabled very rapidly; but the India-rubber Springs appeared to stand the work well.

Mr. W. A. Adams said he was aequainted with these Indiarubber Springs, and had witnessed their working on the Monmouthshire line; it was previously impossible to keep steel springs in order, from the violent jerks they were subjected to, and the substitution of India-rubber for steel in that case was an important improvement. As to the general application of India-rubber Springs, there was a special circumstance in favour of their use in locomotive engines, from the confined position and the want of space to fix a properly proportioned laminated steel spring, which might probably be otherwise made to work satisfactorily; but the steel springs generally used in locomotives were so short and stiff, that their elastic action was exceedingly imperfect, and they were consequently ill suited to withstand the violent concussions of a rough road. In the bearing springs of carriages the case was very different, and a long thin laminated spring was employed, which had a very easy, elastic action, so that in that case the advantage would be less felt of the substitution of India-rubber for steel. In applying the India-rubber Springs to carriages, it had to be observed that the bearing of the frame would be on four points only, instead of eight, requiring a stronger frame or cross-bars to distribute the strain.

Mr. Allan said he had made some trial of these India-rubber Bearing Springs on engines, and they worked very well-but he found them too elastic and liable to produce a jumping action; but the springs he had tried were of the kind first described, without provision for checking the rebound of the spring.

The Crairman inquired whether, if such re-action could be removed, the India-rubber Spring would be considered superior to steel? 
Mr. Altun thought that very little friction or resistance would be sufficient to check the re-action, and the India-rubber would then certainly make a very good spring.

Mr. CraIG observed, that the rebound complained of was quite stopped by the little resistance offered by the small second spring that had been subsequently introduced, but it was now found that the objection was quite removed by the water application in the new Compound Spring.

Mr. Clift inquired whether any difference was found between winter and summer in the action of the India-rubber? whether there was any more oscillation observed in hot than in cold weather? and whether the India-rubber was liable to any injury by the heat to which it was liable to be exposed from the boiler or fire-box of the engine?

Mr. Craig replied, that the India-rubber was not affected by the temperature, and no effect was found during the last severe winter; also in two tank engines one pair of the India-rubber Springs was exposed to great heat, probably as much as $240^{\circ}$, being very near the fire-box, but there was no perceptible effect. The material used for the springs was Molton's Prepared India-rubber; the raw gum would not stand exposure to heat, and the constant compression and elastic action.

The Chatranan inquired what pressure there was upon the India-rubber when the springs were at work?

Mr. Craig replied, that the vertical pressure on the end of the India-rubber Cylinder, in the engine bearing springs, amounted to about $1 \frac{1}{2} \mathrm{cwt}$. per square inch; a weight of $4 \frac{1}{2}$ tons being supported on a cylinder 9 inches diameter, having a $1 \frac{3}{4}$-inch hole in the centre. In the Hydro-Pneumatic Spring the pressure on the Indiarubber was about 2 ewt. per square inch; he intended trying the exact pressure of the water with a Bourdon's Pressure Gauge, but had not been able to complete the experiments in time for the present meeting.

Mr. E. A. CowPER observed, that he understood a considerable trial of India-rubber springs had been made on engines upon the London and North-Western Railway, and inquired what kind of spring had been applied there, and what were the results? He had 
also heard that on the Great Western they used India-rubber Springs, and now never hung an engine any other way.

Mr. Craig replied that the springs tried on the London and North-Western were with two or three cylinders of India-rubber, similar to the first arrangement described, and they were working very satisfactorily, and he believed were preferred to steel springs.

The Chalrman inquired the relative cost of India-rubber and Steel Springs?

Mr. Crata said that the cost of the India-rubber Springs did not in any case exceed that of steel. Waggon springs were about £3 18s. per set, but engine springs were considerably less expensive than steel, there being so much greater proportionate weight of steel in the ordinary springs. By the introduction of water in the Improved Springs, the quantity of India rubber to support the same weight was reduced from $20 \mathrm{lbs}$. to $12 \mathrm{lbs}$. in each spring, which, at the cost of two shillings per pound, effected a considerable saving in the expense.

Mr. H. WRIGHT observed that he was now making a number of waggons with the India-rubber Bearing Springs, in which a compact and economical arrangement of the spring was adopted, applicable to the ordinary construction of waggon frames. A specimen of the spring and axle-box was exhibited to the meeting.

The Chainman asked whether it had been found that an actual saving in oil or grease was effected by the use of the India-rubber Springs?

Mr. Crafg said that considerable saving in this respect had been observed, but he was not able to give the exact results, and he would make a comparative trial for the purpose of ascertaining it ; he considered that the removal of the harsh jerks that occurred with the rigid steel springs prevented waste, and caused the lubrication to be more perfect.

The Chairman observed, that he hoped Mr. Craig would continue his experiments on the application of India-rubber to Springs, and report the result at a future meeting; he proposed a vote of thanks to Mr. Craig for his Paper, which was passed. 
RAILWAY AXIE LUBRICATION.

The following, by Mr. W. Bridges Adams, of London, was then read :- 
INDIA-RUBBER SPRINGS.

Engue Bearing Sprna

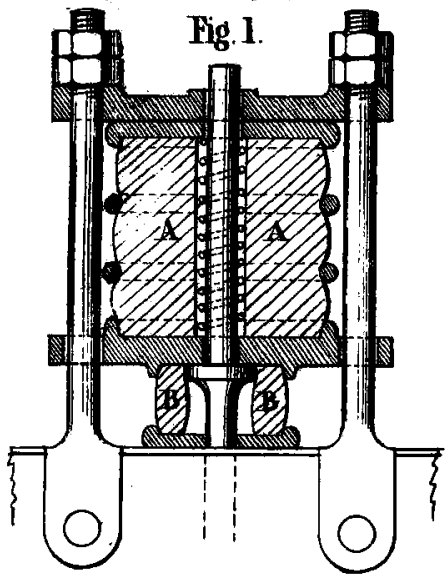

Triple Bearing Spring

Fig. 2.

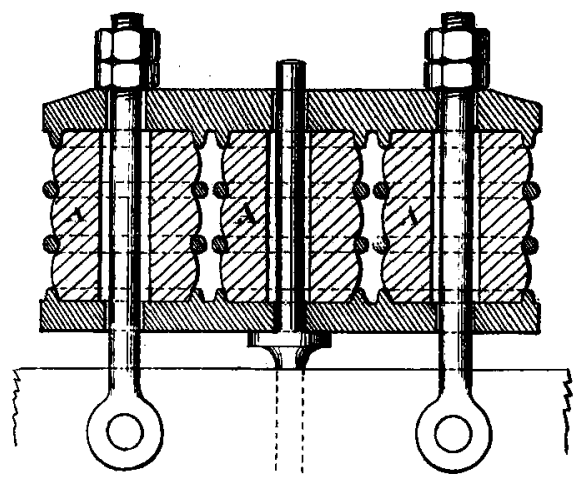

Fig. 4

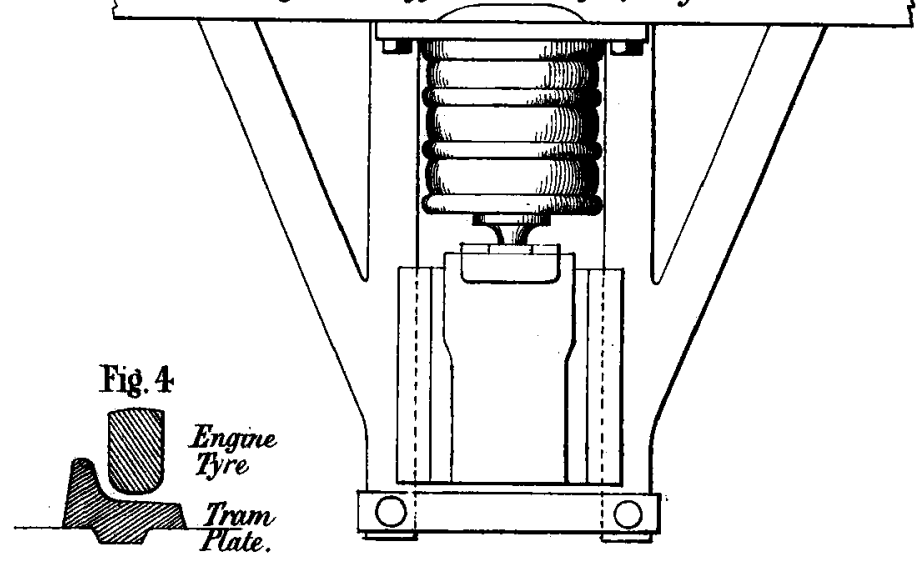

Fig. 3. Waggon Bearing Spring

Fig. 5.

Engine Draw sprin.

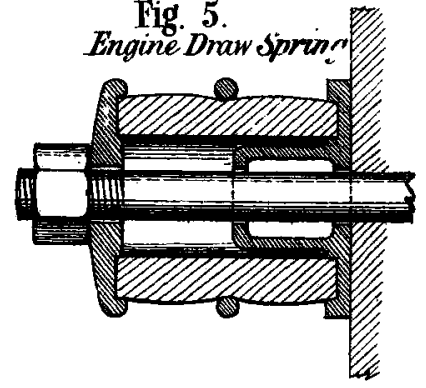

Scale $1 / 10^{\text {th }}$, ?

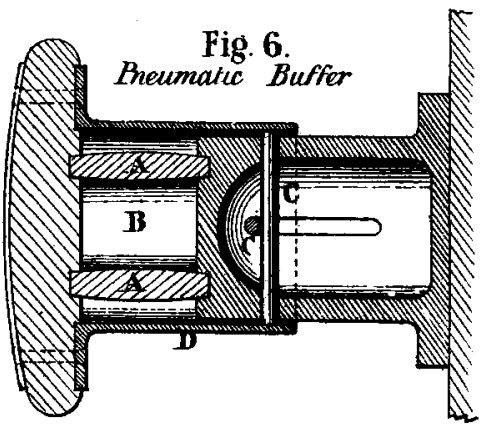

72

24 Inches

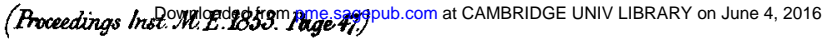


INDIA RUBBER SPRINGS.

Plate 10.

Fig. 7.

Hydro-Pneumatic Engune Spring.

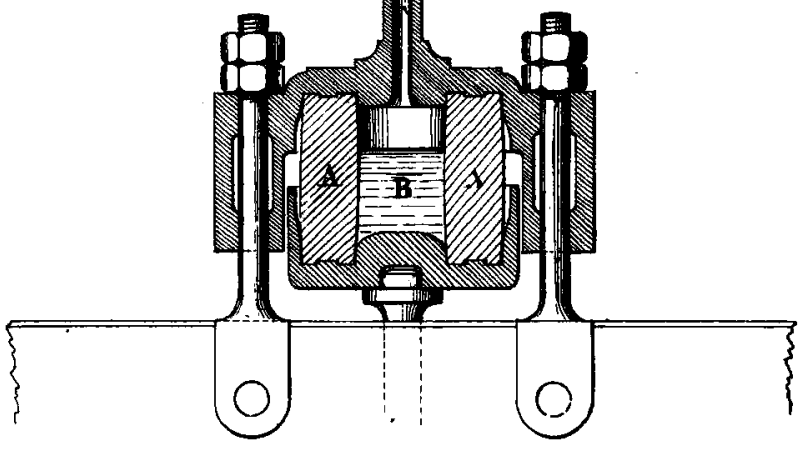

Fig. 8. Improved Hydro-Ineumatic Spring

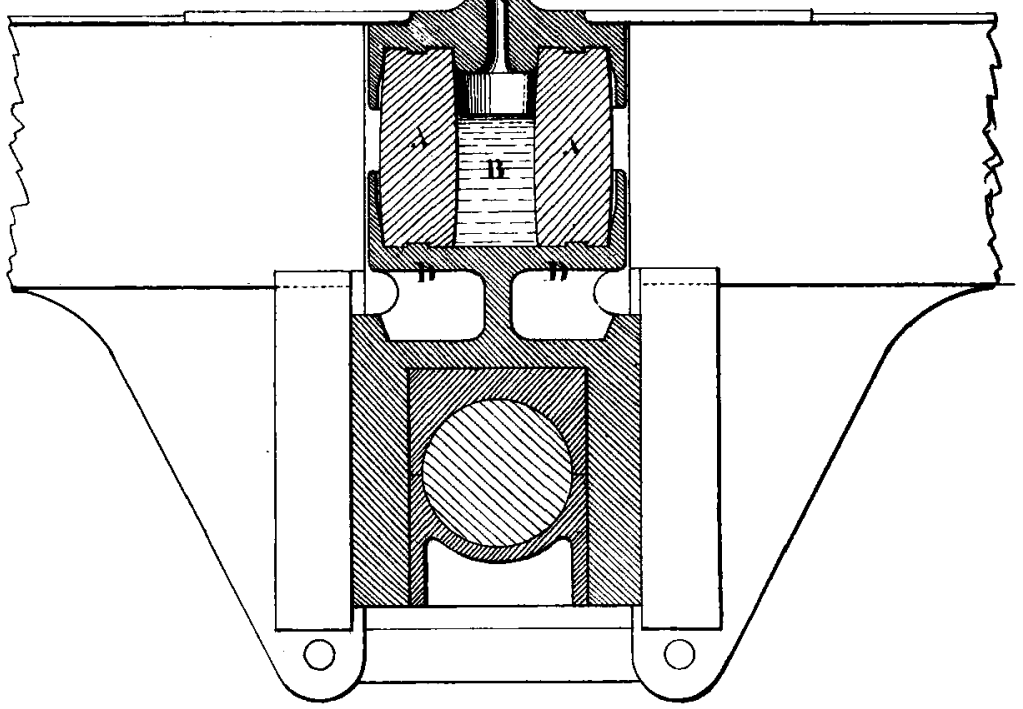

Fig. 9. Waggon Draw Spring.

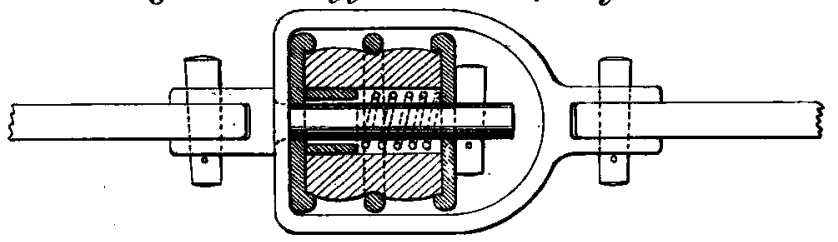

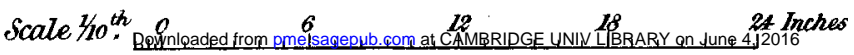

